\title{
A sangre y fuego. Nuevos datos sobre la metalurgia Aguada
}

\section{RESUMEN}

Las placas de metal figuran entre los ítemes más característicos de la cultura material de Aguada. Se conocen poco más de 30 ejemplares, los cuales se encuentran dispersos en colecciones de América y Europa y muy pocos de ellos fueron sometidos a análisis técnicos. En esta oportunidad se dan a conocer los resultados de los estudios realizados sobre tres placas Aguada, orientados a obtener información sobre las cualidades tecnológicas de los materiales, aplicable al conocimiento de la dinámica sociohistórica de la época. En tal sentido, los datos son discutidos considerando la composición de las piezas y los métodos de manufactura puestos en práctica, adelantándose hipótesis sobre la trayectoria de la tecnología metalúrgica en el marco de las condiciones sociales, políticas e ideológicas dominantes.

Palabras claves: placas de metal - La Aguada - análisis técnicos - condiciones sociohistóricas.

\section{ABSTRACT}

Metal plaques are among the most characteristic items of Aguada's material culture. Somewhat more than thirty plaques are known, dispersed in American and European collections, but only a few have been subjected to technical analysis. Here we give the results of studies made on three Aguada plaques to obtain information on the technological qualities of the materials, so as to gain knowledge about the sociohistorical dynamics of the epoch. Data are discussed taking into account the manufacturing methods of metal pieces and their composition in order to advance on hypothesis for the trayectory of metallurgical technology within the the framework of dominating social, political and ideological conditions.

Key words: metal plaque - La Aguada - technical analysis - sociohistorical conditions.

Recibido: marzo 2002. Manuscrito revisado aceptado: octubre 2003.

\section{Introducción}

La metalurgia prehispánica en el Noroeste Argentino se desarrolló de forma independiente a los

1 Museo Etnográfico Juan B. Ambrosetti, Moreno 350 (1091) Buenos Aires. Email: zangolez@yahoo.com tradicionalmente considerados "centros de invención” de los Andes (Figura 1). En la región, como en el resto del espacio andino, hubo una predilección por el trabajo del cobre y sus aleaciones, pero los objetos manufacturados acreditaron una definida identidad en sus rasgos estilísticos y, en un nivel más profundo, en la forma en que los materiales fueron procesados y en las innovaciones técnicas desarrolladas a tal fin. Hacia los momentos tardíos, los artesanos pusieron de manifiesto una extraordinaria capacidad para controlar la compleja interacción de las variables tecnológicas, llegando a producir en bronce estañífero algunos de los objetos precolombinos más voluminosos conocidos. Los ejemplos más ilustrativos lo constituyen las campanas ovales "santamarianas", entre las cuales se computan ejemplares que superan los $3 \mathrm{k}$ de peso. En su momento, los administradores del estado incaico supieron aprovechar el entrenamiento y la destreza de los metalurgistas locales para amplificar la escala de producción en función de los intereses del poder central.

El conocimiento acerca de los inicios de la metalurgia en la región es aún fragmentario. Algunos datos (A. R. González 1959; Fester 1962; Ziobrowski et al. 1996) ponen de relieve el temprano uso de la aleación de cobre y arsénico en el área centro-oriental de Catamarca (Pérez Gollán 1991; L. R. González 1994a, 2001), situación que coloca en discusión a los modelos del desarrollo de la metalurgia planteados desde los Andes Centrales (p.e., Lechtman 1980: 296, 1996: 478; Bray 1991:59; Shimada 1994: 40-41; Lambert 1997: 182). De igual modo, todo apunta a indicar que dicha área (ver Figura 1) fue el escenario de la puesta a punto del bronce estañífero, en épocas tempranas y sin la intervención de influencias externas (L. R. González 1994a, 1999; A. R. González 1998: 94-95; West 1994: 7; Hosler 1994: 179). No es casual que fuera en la zona mencionada donde, al calor de las condiciones sociohistóricas que impulsaron el proceso cultural que conocemos como Aguada, se establecieran las bases del estilo tec- 


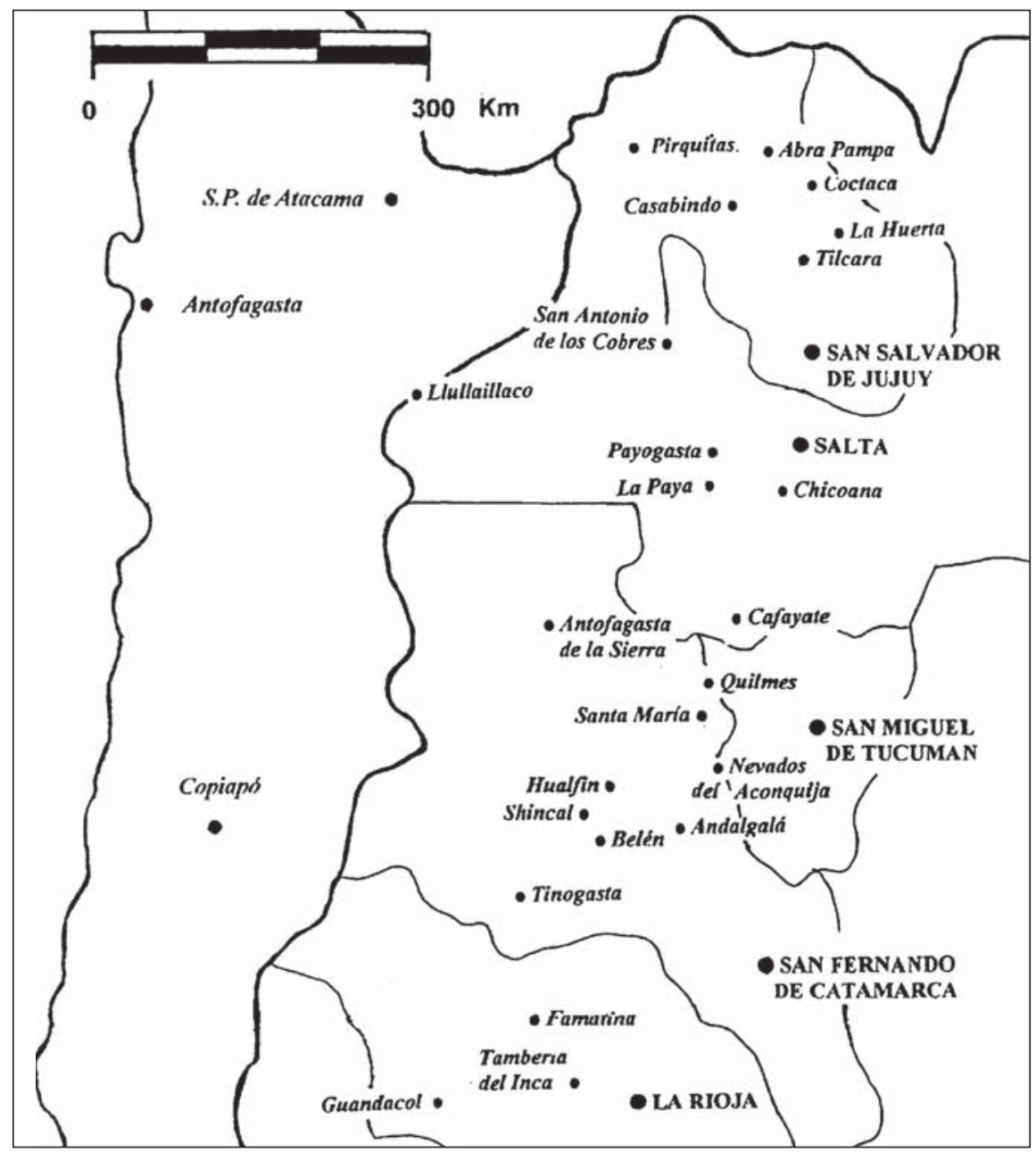

Figura 1. Región del Noroeste Argentino.

nológico que caracterizaría la trayectoria de la metalurgia en los siglos posteriores.

Si bien el conjunto de los hallazgos de objetos metálicos Aguada, en particular en los contextos funerarios del centro de la provincia de Catamarca, muestra un variado repertorio de piezas de función utilitaria (agujas, cinceles, punzones, pinzas), el grueso de la producción parece haber estado orientado a la obtención de piezas ornamentales (A. R. González 1998: 367). Entre éstas, las más llamativas son las placas, sobresaliendo por su relativa escasez (se conocen, al momento, poco más de 30 ejemplares), la detallada ejecución de sus motivos decorativos y la carga simbólica de la iconografía. Precisamente, son las particulares características de los elementos iconográficos las que permiten asignar la pertenencia a la tradición
Aguada de las placas conocidas. No obstante, la gran mayoría de estos objetos carece de registros sistemáticos de hallazgo, lo que conlleva problemas serios a la hora de establecer procedencias y evaluar la distribución espacial de los materiales. Por otro lado, muchas de las piezas en la actualidad se encuentran aisladas en colecciones de América y Europa, públicas y privadas, lo que dificulta tener contacto con ellas, sobre todo para estudios que vayan más allá de las cualidades de su superficie.

Esta circunstancia podría explicar, en parte, la escasez de datos disponibles sobre las características técnológicas de estos materiales. El presente trabajo se orienta en tal sentido, dando a conocer la información obtenida en estudios de laboratorio llevados a cabo sobre tres placas de la familia 
Aguada, dos de ellas no publicadas hasta el momento. Estos estudios, enmarcados en un programa de investigación más amplio acerca de la metalurgia prehispánica del Noroeste Argentino (N.O.A.) y que es desarrollado desde hace varios años (L. R. González 1997; L. R. González et al. 1999; L. R. González y Vargas 1999), además de la determinación de la composición de los materiales procuraron establecer los procesos de manufactura de las piezas. Tal información constituye por sí un avance en el conocimiento de la trayectoria de la tecnología en la región pero, asimismo, aspira a contribuir a la discusión de las condiciones sociohistóricas que rodearon a las actividades productivas.

\section{Tecnología metalúrgica y relaciones sociales}

Los estudios sobre la metalurgia del pasado se desenvolvieron durante décadas bajo imperativos teóricos, implícitos o explícitos, enraizados en el evolucionismo unilineal y el materialismo vulgar, con una visión sesgada desde la moderna sociedad industrial. De tal modo, los esfuerzos de investigación mostraron una marcada tendencia a establecer los "qué" y los "cómo" de la tecnología, abordándola bajo el supuesto que su desarrollo respondió a una lógica propia divorciada de las condiciones sociohistóricas en las que había operado. No hace tanto tiempo desde que comenzaran a alzarse las voces que sostenían que, tan importante como categorizar los materiales metálicos y describir los procedimientos de manufactura, para una comprensión adecuada de los comportamientos tecnológicos del pasado se requería atender a los "por qué" subyacentes a tales comportamientos. Ello conducía a considerar a la metalurgia como un fenómeno cultural, por lo cual el análisis debía tomar en cuenta los valores, símbolos y actitudes sociales a la hora de evaluar las elecciones técnicas puestas en práctica por los productores y el desempeño de los bienes obtenidos (L. R. González 2001).

"Manufacturing an object always involves accomodation between the properties of the material from which the object is made and the object's design: the possibilities and constraints any material precedents in handling versus how we want the material to perform. The fact that the physical properties of natural material are inmutable and invariant wherever they are found means that variations in the way culture-bound practitioners manage these materials reflect cultural choices. Our ability to identify culturals decisions and choices in the technologies behind object production lies precisely in this regularity in the physics of matter" (Lechtman 1999: 223). ${ }^{2}$

La transformación de materias primas en artefactos, a través del trabajo humano, implicó, por un lado, que estas materias transformadas fueron "recreadas" e incorporadas a un entramado cultural particular, con una carga de significación específica. Por otra parte, el proceso productivo entrañó relaciones sociales, de las que participaron productores y consumidores y que estuvieron fundadas en concretas condiciones materiales de existencia. En consecuencia, la tecnología fue mucho más que los recursos disponibles y los procesos de transformación aplicados. Involucró, sobre todo, contextos socioculturales que legitimaron y determinaron qué producir y cómo hacerlo, así como el destino y las prescripciones de uso de los productos. Lejos de responder a una evolución "natural", la trayectoria de la metalurgia en el pasado estuvo determinada por una dialéctica entre la física y la química de la producción, y los elementos superestructurales que dictaminaron sobre el modo en que estos factores debían ser acomodados dentro de la representación dominante del mundo y de la sociedad.

La producción de bienes de metal, con justicia, ha sido considerada como la actividad más compleja encarada por el hombre y cuyo desarrollo marchó codo a codo con el aumento en la complejidad de las organizaciones sociales (Childe 1930 y 1936). De hecho, en el N.O.A., la sofisticación técnica aplicada y la escala de las actividades pueden verse como una metáfora del surgimiento y consolidación de organizaciones políticas en las cuales la desigualdad en el acceso a poder y recursos fue institucionalizado y grupos minoritarios se reservaron el control del capital económico y simbólico de las comunidades. El auspicio y el control sobre la producción y distribución de bienes de metal constituyeron herramientas estratégicas para fundar operaciones políticas y económicas que apuntalaran la posición de las élites gobernantes. Pocos discuten que las prácticas metalúrgicas requirieron la intervención, en algún grado, de mano de obra especializada

2 Ver también Hosler (1994) y Lahiri (1995). 
(Bronson 1996: 179), lo cual conllevó el sostenimiento, a través de los recursos comunitarios, de grupos artesanales variablemente desafectados de obligaciones relacionadas con las actividades cotidianas (Tarragó y L. R. González 1996). Al mismo tiempo, la complejidad y los requerimientos de la producción (energía en trabajo, movilización de materias primas, habilidad y entrenamiento de los operarios) otorgaban a esas elites, a través del control productivo, la oportunidad de desplazar a eventuales competidores por los espacios de poder. De igual modo, la distribución pautada de los bienes obtenidos podía aplicarse a redes de intercambio extrarregionales que fortalecerían su posición dominante (Tarragó et al. 1997).

No parece un dato menor, en tal sentido, que en el N.O.A. el énfasis productivo estuviera volcado hacia bienes sin directa vinculación con lo práctico-utilitario sino hacia aquellos cuya propiedad, uso y exhibición comunicaba posiciones de prestigio y poder social. A partir de sus conexiones con los grandes temas míticos del mundo andino (Lechtman 1991 y 1999), los metales eran materiales ideales para resumir y potenciar una ideología funcional a los intereses de los grupos de poder. El campo más fructífero para divulgar esta ideología era el religioso, en el cual la vida cotidiana podía ser remitida a un orden cósmico ahistórico e inmutable, naturalizando los liderazgos a través de su actuación como intermediarios entre los comunes y las potencias sobrenaturales. Como otros autores han señalado (Pérez Gollán 1986; A. R. González 1992 y 1998; A. R. González et al. 2000; Bovisio 1994), las placas del Período de Integración (ca. 450-850 DC) materializaron los fundamentos de un universo mítico pan-andino cuya manipulación fue clave en la fundación de las organizaciones sociales complejas. Por tal razón, estas piezas constituyen uno de los más ilustrativos ejemplos de la articulación entre el desarrollo de las bases productivas y la superestructura político-ideológica inherente a aquella complejidad.

\section{Las placas Aguada}

Los objetos de que nos ocupamos reconocen antecedentes en piezas similares de contorno oval, pero de mucha mayor simplicidad de manufactura (A. R. González 1992). Las placas del Período de Integración, momento histórico hegemonizado por el fenómeno sociocultural Aguada, desde lo tecnológico evidencian la introducción de por lo menos dos importantes innovaciones en el modo de procesar el metal: por una parte, la preparación de la aleación de cobre y estaño, y por otra, el empleo de un sofisticado método de moldeo, el de la cera perdida. Se trata de piezas de mediano tamaño. La dimensión máxima promedio se ubica en los $150 \mathrm{~mm}$, aunque el Disco Hirsch I (Figura $2 \mathrm{~b}$ ) ostenta un diámetro de $207 \mathrm{~mm}$. Desde lo formal, los materiales conocidos fueron clasificados de acuerdo a dos variables (A. R. González 1998: 99; A. R. González et al. 2000): su forma y su decoración. En cuanto al primer aspecto, se distinguieron los contornos circulares, rectangulares y los excepcionales. En esta última categoría se computa una única pieza, la denominada Placa Ross (Figura 2a). De acuerdo a la decoración, fueron reconocidos tres tipos: el "Personaje de las Manos Vacías" (Figuras 2b y 2e), el "Sacrificador" (Figuras 2c y 2d) y "Dos o Más Personajes" (Figura 2f). En todos los casos, el tema iconográfico central es una figura antropomorfa con distintas variantes, presentado de frente, con los brazos flexionados a los costados, un adorno cefálico y ataviado con una túnica que suele mostrar dibujos de escalonados, espirales y líneas rectas. En el caso de El Sacrificador, de los brazos cuelgan hachas, cuchillos o representaciones de cabezas cercenadas. Acompañando a la figura central suelen incluirse seres zoomorfos, felinos, saurios o aves.

Es sugestivo que, de acuerdo a los registros de hallazgos disponibles, una sola de estas placas tendría como procedencia el área centro-oriental de Catamarca (ver Figura 1), la cual podría considerarse como corazón del territorio Aguada (A. R. González 1998: 236). De igual modo esta pieza, el Disco de Lafone Quevedo (Figura 2e), procedente de Chaquiago (Lafone Quevedo 1890; Easby 1966: 74-76) y del tipo "Personaje de las Manos Vacías", es la más famosa de la familia. La gran mayoría de las piezas fueron denunciadas en ámbitos más distantes, en ocasiones fuera del N.O.A. Al respecto se propuso que, en el pasado, shamanes itinerantes habrían trasladado los materiales como parte de la política de difusión del culto religioso (A. R. González 1998: 100, 182). No obstante, el centro de fabricación habría sido el N.O.A. (A.R. González 1992: 196 y 1998: $99,169)$. 


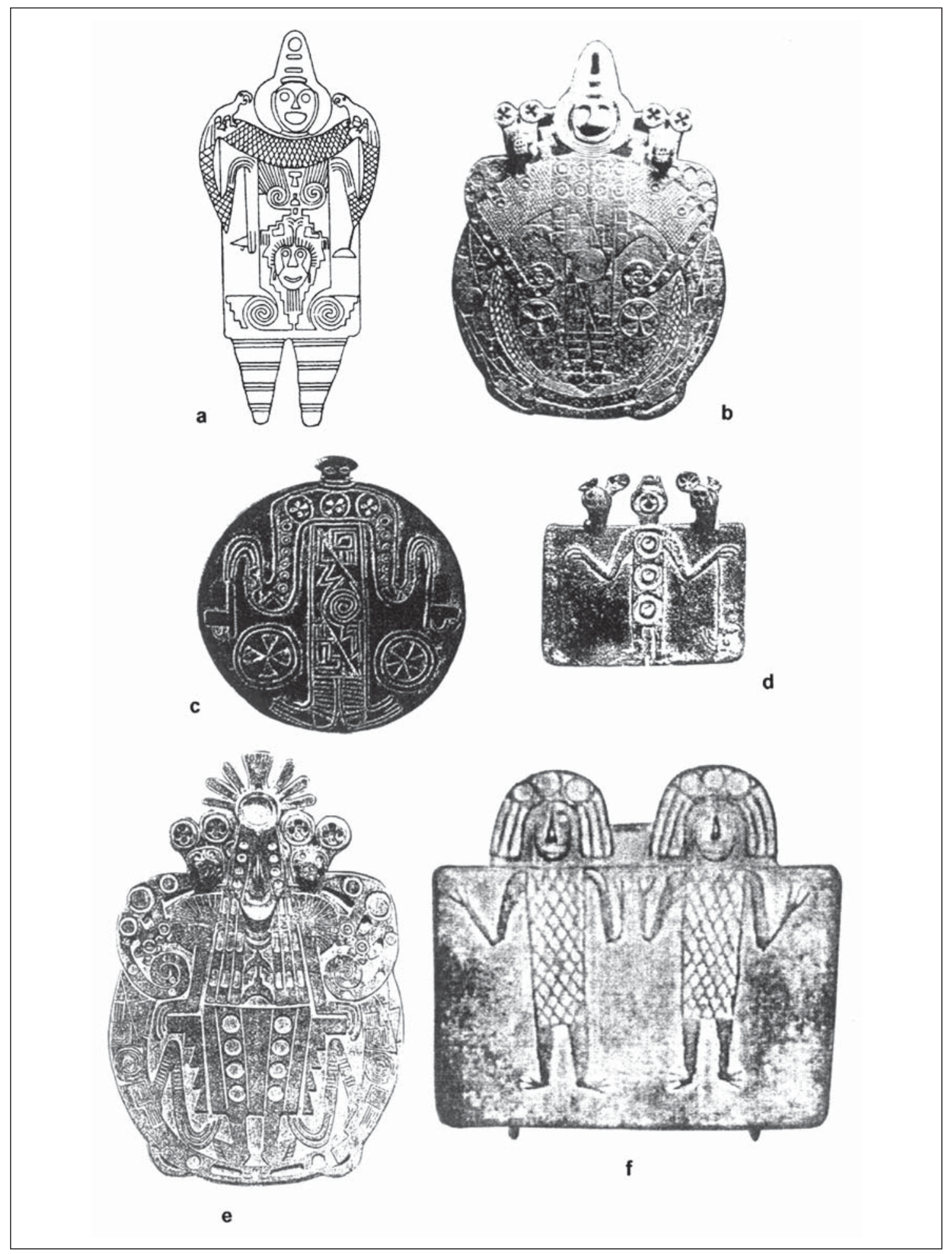

Figura 2. Placas Aguada: a) Placa de Beni; b) Placa Hirsch I; c) Placa del Musée de l’Homme; d) Placa de Denver; e) Placa Lafone Quevedo; f) sin datos, en Scott 1998. 


\section{Antecedentes de estudios}

Como se expresara con anterioridad, los estudios técnicos realizados sobre placas de la familia fueron escasos. De hecho, hasta donde conozco, se publicaron sólo tres. El primer trabajo exhaustivo fue efectuado hace poco más de una decena de años (Biloni et al. 1990), sobre el mencionado "Disco de Lafone Quevedo", un siglo después de su primera descripción (Lafone Quevedo 1890). De acuerdo a su ornamentación, se propuso que fue manufacturado entre el 600 y 700 DC. Acredita un diámetro en torno a los $11 \mathrm{~cm}$ y su espesor, notablemente regular, es de unos $3 \mathrm{~mm}$. En su cara decorada se advierte un personaje central complejamente ataviado, con dos felinos de largas colas y prominentes orejas sobre sus hombros y saurios a sus pies (Figura 2e). De acuerdo a los estudios, la pieza es de bronce, con alrededor de $2.5 \%$ de estaño y menos del $0.3 \%$ de arsénico (Emerich 1992: 214). La precisión de algunos detalles decorativos y las características metalográficas sugieren que el disco fue colado según la técnica de cera perdida (Easby 1966: 7476), y posteriormente, terminado con suaves pulidos y burilados.

Lechtman (1991: 78) dio a conocer los resultados del análisis de la composición de una placa circular que, de acuerdo a la ilustración que se presenta, sufrió algunos deterioros. Es probable que la cabeza humana sobresaliente en el borde superior se haya perdido por rotura y los rasgos decorativos del cuerpo de la placa no aparecen muy nítidos. Se trataría del tipo "Personaje de las Manos Vacías". La autora indicó que la pieza fue realizada por vaciado en molde de cera perdida, a partir de la inscripción de las finas líneas que forman los dedos de la figura central. En el análisis fue detectado cobre en un $97 \%$ y estaño en $1.31 \%$, además de cantidades minoritarias de hierro, cinc, níquel, plata y plomo.

El restante estudio fue dado a conocer por Scott (1998: 101-102), quien indicó que para la placa proviene del N.O.A, no hay referencias sobre el lugar preciso de hallazgo ni de su actual depósito. La pieza, rectangular, con dos personajes antropomorfos cuyas cabezas asoman por sobre el borde superior, pesa $87.80 \mathrm{~g}$ y mide 84 por 51 $\mathrm{mm}$, con un espesor en torno a los $2 \mathrm{~mm}$ (Figura 2f). Respecto de su manufactura, se dictaminó que fue empleado el método de cera perdida. El aná- lisis químico arrojó la siguiente composición: cobre $(88 \%)$, arsénico $(0.8 \%)$, estaño $(8 \%)$, antimonio $(2.7 \%)$ y trazas de hierro.

\section{Estudios sobre tres placas Aguada}

Las placas sobre las que informamos pertenecen a dos colecciones privadas y fueron especialmente cedidas para los estudios de laboratorio. Estos incluyeron relevamientos dimensionales, observaciones con lupa binocular y microscopio electrónico de barrido (SEM) a diferentes aumentos. Las determinaciones cuantitativas de composición se realizaron con energía dispersiva en Rayos X (EDAX) mediante un equipo acoplado al SEM. Los resultados que se consignan para cada objeto constituyen el promedio de entre cinco y ocho mediciones en distintos puntos de las caras anteriores y posteriores. No fueron tenidos en cuenta los elementos que componen la pátina superficial (por lo general, $\mathrm{Na}, \mathrm{Si}, \mathrm{S}, \mathrm{Cl}$ y $\mathrm{Ca}$ ). Análisis microestructurales por metalografías fueron efectuados de acuerdo a las especificaciones de la norma ASTM-1351. En cada caso un pequeño sector de la superficie de las piezas fue desbastada con papeles abrasivos de malla 320, 400, 600 y 1000. Posteriormente se pulió con paños con pasta diamantada de 7 y $1 \mathrm{um}$. La microestructura fue revelada con microataques con ajuste a la norma ASTM E-407. ${ }^{3}$

\section{Placa $N^{\circ} 1$ (Circular/Sacrificador)}

El hallazgo de esta pieza, designada como Placa Bercheni y de forma discoidal, se produjo en la zona del río Levallén, en la provincia de Salta (A. R. González et al. 2000). El disco está rodeado por una banda concéntrica unida por cinco "puentes" y en la parte superior se desprenden dos apéndices (Figuras 3a y 3b). Los diseños escultóricos y motivos decorativos con líneas en relieve se concentran casi exclusivamente en la cara anterior. El motivo iconográfico dominante es una representación antropomorfa central con un tocado que cae a los costados del rostro. El personaje presenta los brazos flexionados y manos con tres largos dedos. De cada brazo cuelgan sendos instrumentos, un cuchillo y un hacha. Las piernas

\footnotetext{
3 La totalidad de los estudios fueron realizados en los laboratorios del Centro Atómico Constituyentes, de la Comisión Nacional de Energía Atómica.
} 


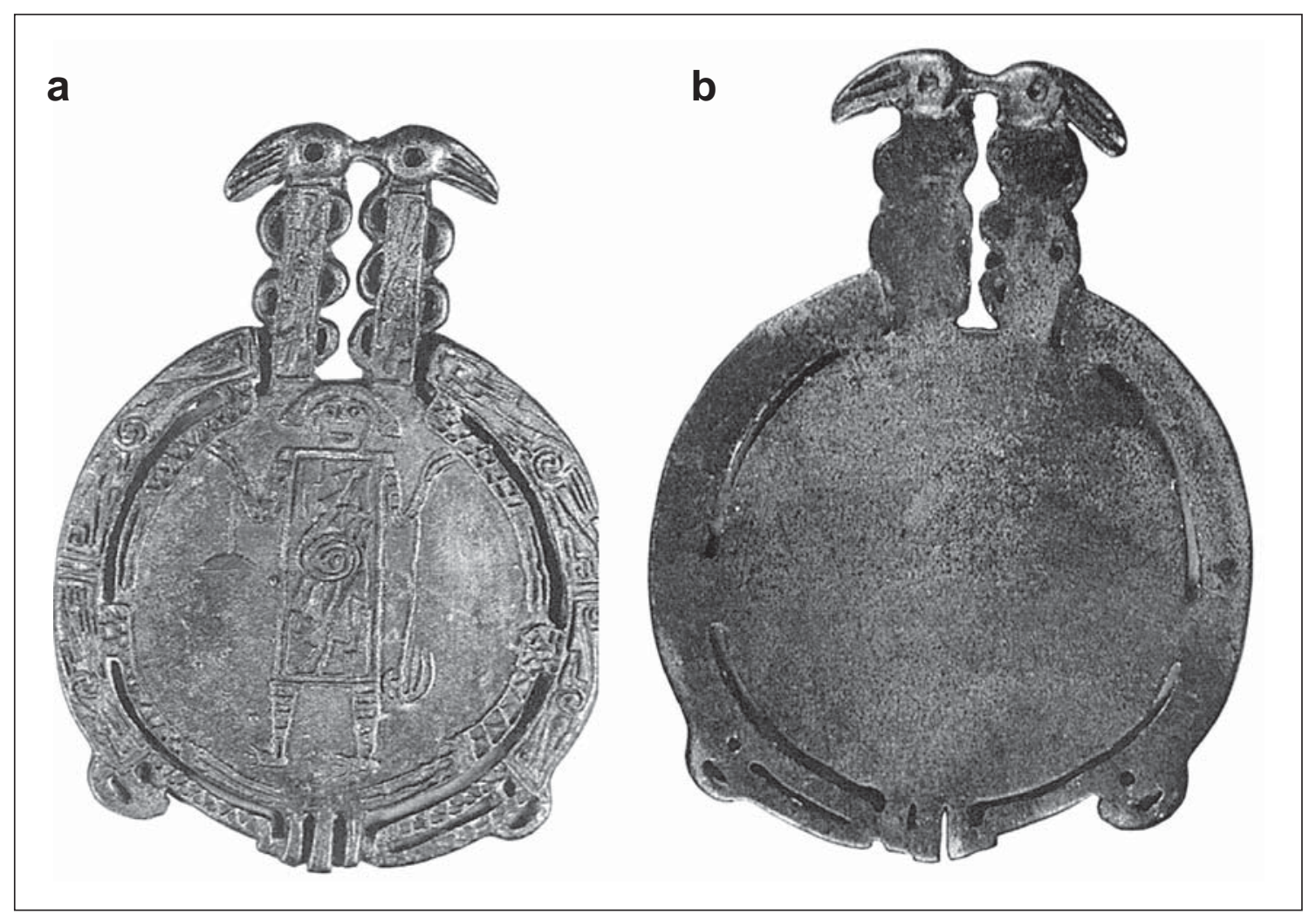

Figura 3. Placa $\mathrm{N}^{\mathrm{o}}$ 1: a) frente; b) dorso.

culminan en pies con tres dedos cada uno y que se orientan hacia la derecha del cuerpo.

La banda concéntrica que rodea al disco incluye dos seres sauriformes. Los puentes de unión con el disco interno tienen lugar mediante las patas de los animales y con tres cortos apéndices verticales que se ubican en la zona inferior, donde coinciden los hocicos de los seres. Al saurio a la derecha del personaje central, le falta la mandíbula superior. Los apéndices que se elevan en la parte superior del disco, por sobre el personaje antropomorfo, consisten en dos barras separadas, con semicírculos a los lados. Las barras terminan en cabezas ornitomorfas, en las cuales se han señalado los ojos, con una depresión central, así como los picos. Las cabezas se colocaron en direcciones opuestas, es decir, que los picos se orientan hacia afuera. El dorso de la pieza es completamente liso, a excepción de la cabeza de los pájaros, las que han sido conformadas respetando el volumen que muestran en la cara anterior. Las principales dimensiones registradas son las siguientes: 1) alto total (incluyendo apéndices): $118.1 \mathrm{~mm}$; 2) diáme- tro total (incluyendo bandas concéntricas): entre 88.5 y $90 \mathrm{~mm}$. El promedio de cinco mediciones es de $89.25 \mathrm{~mm}$; 3) espesor en las zonas lisas; entre 2.18 y $2.67 \mathrm{~mm}$. El promedio de seis mediciones es de $2.41 \mathrm{~mm}$; 4) espesor de zonas en relieve: entre 2.9 y $4.2 \mathrm{~mm}$; 5) Peso: $115 \pm 1 \mathrm{~g}$.

La inspección visual a diferentes aumentos permitió detectar algunos detalles relevantes para un acercamiento a las técnicas puestas en práctica para manufacturar la pieza. En varios sectores se advirtieron partículas de una sustancia blanca adherida al metal, con tendencia a concentrarse en los intersticios formados por los detalles decorativos (Figuras 4a, 4b y 4c). La experiencia en estudios de otros objetos de la región nos permite asumir que la sustancia es fosfato de calcio y constituía el recubrimiento de la cavidad interna del molde utilizado. Pudo observarse, asimismo, que la mayor parte de los motivos decorativos en alto relieve presentan laterales biselados en ángulos obtusos respecto de la superficie de la pieza. Este detalle es interpretado como un comportamiento intencional destinado a lograr un más sencillo 
despegue de la pieza fundida, evitando anclajes en el refractario.

En general, los defectos de fabricación son de índole menor. Por ejemplo, pudo establecerse que la falta de la mandíbula superior del saurio derecho no responde a una rotura, como parecía a ojo desnudo, sino que obedece a un imperfecto llenado del molde durante la colada de metal. En el mismo sector de la pieza, el borde de lo que sería la oreja del saurio tiene una terminación redondeada, lo que sugiere un fenómeno de solidificación con, probablemente, pérdida de fluidez del metal colado derivado, a su vez, por enfriamiento (Figura 4a). Se interpreta que este fenómeno indica que la boca de colada del molde se encontraba en el punto opuesto, es decir, donde se encuentran los apéndices coronados con cabezas de pá- jaros. Otros defectos, como la solidificación dendrítica que se observó en la superficie del metal en la misma zona del saurio (Figura 4b), apoyan la hipótesis enunciada. También pudo constatarse que en uno de los semicírculos del apéndice superior izquierdo se efectuó una perforación $a$ posteriori de colada la pieza, probablemente para disponer de un lugar para pasar un elemento de sujeción.

La composición promedio de la pieza fue determinada en $85.41 \% \mathrm{Cu}$ y $14.58 \% \mathrm{Sn}$. En la parte posterior del disco fue preparada una zona de la superficie para la obtención de una réplica estructural. En las observaciones sin ataque químico fueron detectados óxidos de cobre en la matriz, los que poseen morfología típica de una fase eutéctica. Las observaciones posteriores se efec-

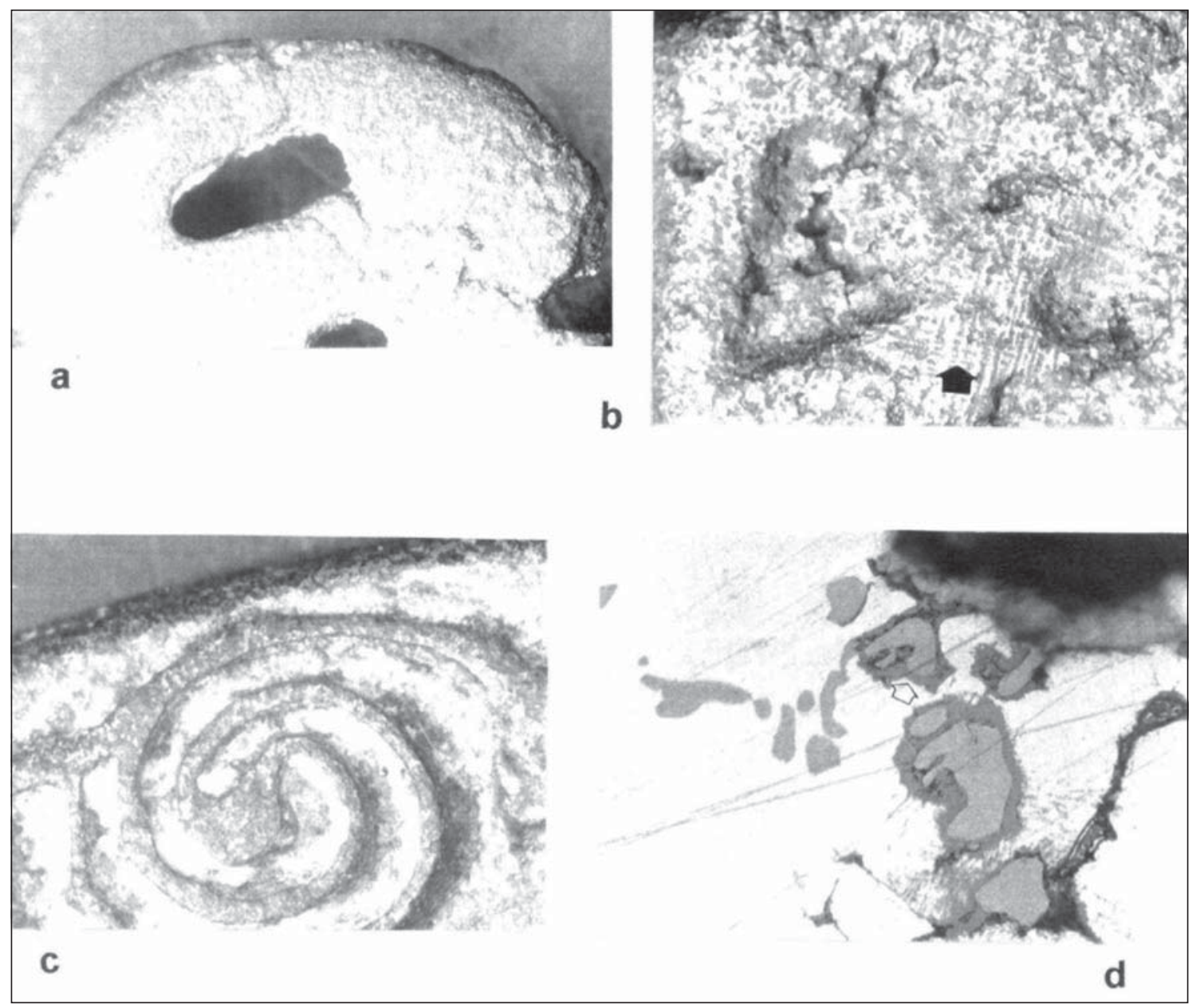

Figura 4. Placa $\mathrm{N}^{\circ}$ 1: a) zona redondeada en la oreja de un saurio; b) estructura de solidificación dendrítica cerca de la oreja de un saurio; c) espiral con recubrimiento blanquecino; d) microestructura (200x) con inclusiones de óxidos globulares. 
tuaron tras el pulido con paños diamantados. La microestructura revelada con el ataque de reactivo $\left(\mathrm{H}_{2} \mathrm{O}, \mathrm{HCl}\right.$ y $\left.\mathrm{Cl}_{3} \mathrm{Fe}\right)$ mostró corresponder a una estructura de solidificación con un eutéctico en los espacios interdendríticos y óxidos globulares (Figura 4d).

\section{Placa No 2 (Rectangular/Sacrificador)}

Este ejemplar no cuenta con información fehaciente acerca de su lugar de hallazgo, tratándose de una placa rectangular con un apéndice. En su cara anterior presenta una figura antropomorfa lograda por líneas en relieve. La cabeza de esta figura, con un complejo tocado, constituye el apéndice, al sobresalir del borde superior de la placa. El anverso no presenta detalles decorativos. La representación antropomorfa se muestra de frente, con los brazos flexionados y adornados por un reticulado que se continúa por el torso. Las manos cuentan con tres largos y finos dedos. Del codo izquierdo cuelga un cuchillo semilunar y de la mano derecha, a su vez, pende un hacha con gancho (Figuras 5 a y 5 b).

El cuerpo del personaje está dividido por una franja diagonal de dos líneas en relieve. En cada uno de los sectores así delimitados se señaló, con una disposición simétrica, un motivo que combina grecas y escalonados. Los pies se disponen de perfil, apuntando hacia direcciones opuestas. En cada pie se identifican tres dedos. La cabeza de la figura, que sobresale del borde superior, parece estar cubierta con una gran máscara zoomorfa en la que se destacan dos rasgos. En primer lugar, un hocico que sobresale del plano principal de la pieza, con el interior hueco. En el frente presenta seis perforaciones (Figura 6a). De este hocico cuelgan, hacia cada lado, largos bigotes. Del cuello del personaje pende un colgante que forma un medallón circular. En segundo término, dos largas orejas que descienden hacia los lados. En el plano frontal de cada una de las orejas fueron dispuestas ocho depresiones circulares (Figura 6c).

La cara posterior de la pieza es completamente lisa, siendo el único rasgo destacable un pequeño agujero pasante que comunica con el interior hueco del hocico del frente. Las dimensiones principales de la pieza son las siguientes: 1) ancho máximo: $882 \mathrm{~mm}$; 2) alto máximo: $941 \mathrm{~mm}$; 3) alto de la placa (sin apéndice): $590 \mathrm{~mm}$; 4) espesores (en sectores lisos): entre 2.39 y $2.96 \mathrm{~mm}$; $5)$ altura de las líneas en relieve (promedio): 0.54 $\mathrm{mm}$; 6) peso: $135 \pm 1 \mathrm{~g}$.

Las observaciones meso y microscópicas permitieron registrar tratamientos diferenciales en la

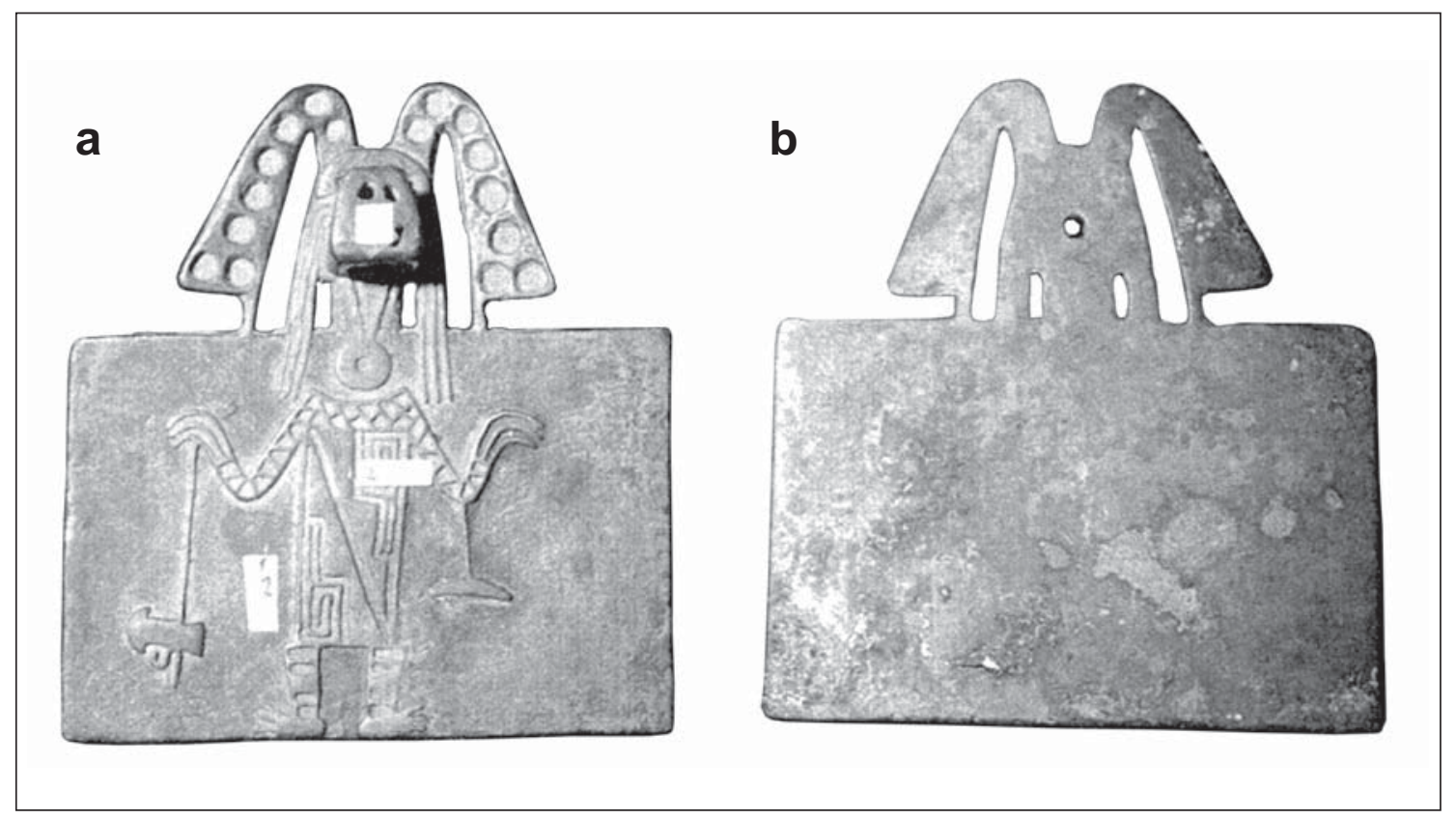

Figura 5. Placa $\mathrm{N}^{\circ}$ 2: a) frente; b) dorso. 


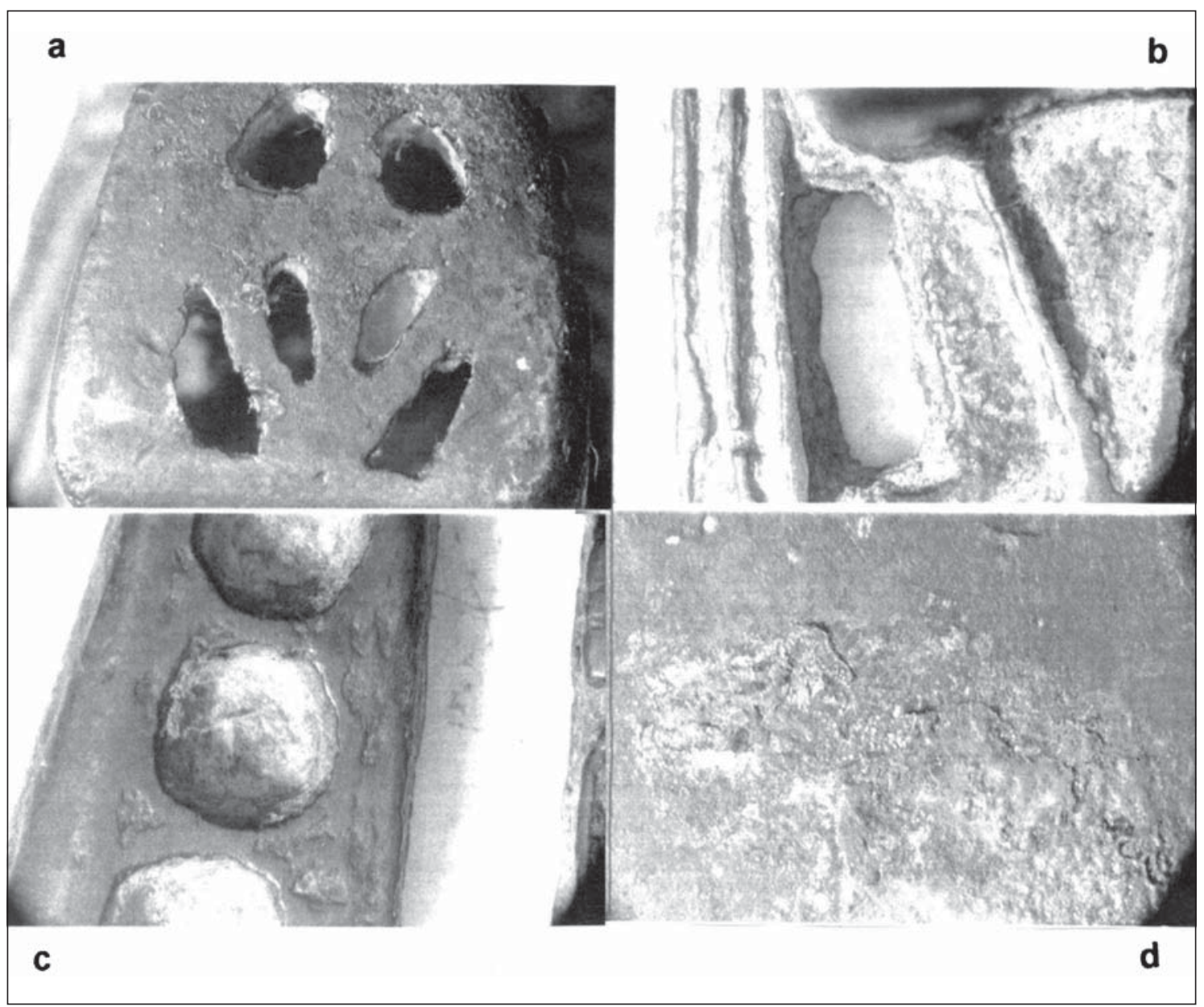

Figura 6. Placa $\mathrm{N}^{\circ}$ 2: a) hocico; b) zona pulida; c) concavidades en una de las orejas; d) área de corrosión en el dorso.

superficie de la pieza. En la zona del hacha que cuelga del brazo derecho del personaje pudo detectarse que la base de la placa que acompaña el relieve muestra, por una parte, una rugosidad que es atribuible al molde utilizado y, por otra, una película blanquecina que puede ser atribuida al recubrimiento del refractario (Figura 6b). La superficie del hacha muestra signos de haber sido pulida, contrastando con la base de la placa señalada previamente. También se observó pulimento en los relieves de los pies y en el medallón que cuelga del cuello del personaje. El hocico de la máscara tiene perforaciones que conectan con una cámara hueca, en cuyo fondo un orificio conduce a la cara posterior de la placa. También hay rastros de pulido, pero no parece haber habido preocupación por retirar rebabas de metal que quedaron en los bordes de las perforaciones (Figura 6a). En ellas se observan, además, depósitos de material blanquecino. El interior de la cámara del hocico muestra rugosidades que probablemente se relacionen con el "noyo" (núcleo refractario que es disgregado luego de la colada para dejar un espacio hueco en la pieza) utilizado en la fundición. Las depresiones ciculares en las orejas son de bordes irregulares, siendo probable que originalmente estuvieran rellenadas con piedras ornamentales. En el reverso de la placa fueron detectados algunos sectores con eflorescencias de corrosión y pérdida de material de superficie, pero con escasa intensidad (Figura 6d). Se prepararon tres incisiones micrométricas en el anverso de la placa, en las cuales se efectuaron mediciones cuantitativas de composición. El promedio de esta composición fue establecido en $96.1 \% \mathrm{Cu}$ y $3.8 \% \mathrm{Sn}$. En la cara posterior de la placa fue pulida una pequeña zona para obtener una réplica estructural. Sobre la superficie sin ataque químico pudo 
observarse una matriz metálica de color uniforme y una estructura de tipo dendrítico correspondiente a óxidos de cobre. Un compuesto correspondiente a la pátina de la pieza, por Difracción de Rayos $\mathrm{X}$ fue identificado como atacamita $\left[\mathrm{Cu}_{2}(\mathrm{OH})_{3}\right.$ $\mathrm{Cl}$. En la observación de la superficie luego del ataque químico se detectaron bordes de granos de forma redondeada y con tendencia equiaxial. Estos bordes son de distintos espesores, por efecto de corrosión diferencial. El tamaño de los monocristales sugiere que, luego de la colada, el metal fue sometido a un enfriado lento. También fueron registrados grupos de finas líneas paralelas que representan líneas de deslizamiento que sugieren que la pieza fue sometida, luego de la colada, a un suave trabajado mecánico por percusión.

\section{Placa No 3 (Rectangular/Sacrificador)}

Para esta pieza tampoco se tienen referencias sobre su procedencia. De las tres estudiadas, es la que mayor simplicidad de detalles decorativos presenta y, al mismo tiempo, evidencia la menor calidad de fabricación. Asimismo, muestra importantes alteraciones por "manoseo" y operaciones de limpieza, presumiblemente derivadas de su actual condición como objeto de exhibición. Se trata de una placa rectangular, con un apéndice superior que constituye la cabeza de una figura antropomorfa inscrita en líneas en relieve en el material (Figuras 7a y 7b). El rostro del personaje presenta la boca marcada con una línea y ostenta una nariz prominente en forma de gota. Los ojos, grandes y circulares, están profundamente marcados en bajo relieve, siendo probable que, originalmente, las cavidades albergaran piedras ornamentales. La cabeza se encuentra rodeada por un tocado semilunar adornado con líneas radiales. Este tocado se une a la cabeza sobre el centro de la frente, pero el metal rellena el espacio aproximadamente de oreja a oreja. A ambos lados del cuello se advierten dos perforaciones de contorno irregular. Por lo menos una de ellas, la derecha, fue realizada o ampliada en frío, luego de colada la pieza. Los bordes del agujero muestran evidencias de presión desde el anverso al reverso. Una fractura horizontal que parte de la perforación y corta la unión del tocado con la placa rectangular, puede haber sido provocada por la tensión derivada de dicho trabajo. En la parte superior del tocado, sobre el borde, es notoria una pequeña imperfección que se corresponde con un

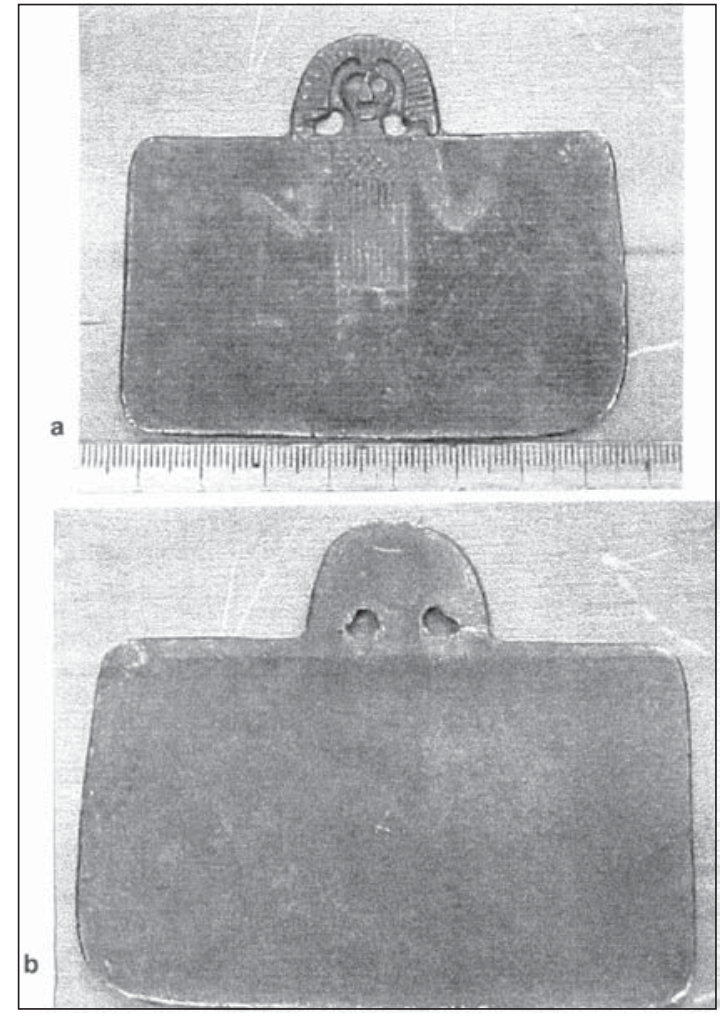

Figura 7. Placa $\mathrm{N}^{\mathrm{o}}$ 3: a) frente; b) dorso.

corte de material, siendo probable que se tratara de la boca de colada del molde.

El cuerpo de la figura, presentada de frente, muestra en la parte superior del pecho un reticulado en diagonal y, más abajo, líneas verticales paralelas. Los brazos, también con un reticulado, están flexionados en los codos y las manos ostentan tres largos dedos. De la muñeca derecha cuelga un hacha. Las piernas son rectangulares alargadas y adornadas con un reticulado cuadrangular. Las líneas se van esfumando hacia abajo, de forma tal que los pies no llegan a aparecer. El dorso de la placa no presenta detalles decorativos. Sí puede observarse una depresión lineal provocada por la presión o percusión de una herramienta en frío, pero de antigua data.

Con un peso de $53.5 \mathrm{~g}$, la placa tiene un ancho máximo de $81 \mathrm{~mm}$ y un alto mínimo de $50 \mathrm{~mm}$. Incluyendo el apéndice cefálico, el alto trepa a 68 $\mathrm{mm}$. El espesor promedio es de $1.7 \mathrm{~mm}$, pero los valores más bajos se registran hacia la izquierda del cuerpo antropomorfo. En este sector, además, se advierte una fractura horizontal y un área de 
rugosidad superficial. La esquina inferior izquierda de la placa tiene un vértice redondeado que no es atribuible a desgaste o trabajo mecánico.

El análisis de composición señaló 5.8\% de estaño, $93.5 \%$ de cobre y $0.7 \%$ de hierro. Como en los casos anteriores, se preparó en el reverso un área mínima para estudios metalográficos. Estos revelaron una estructura dendrítica con óxidos de cobre que tienden a alinearse a lo largo de la fractura del material señalada (Figura 8).

De acuerdo a la información obtenida, la pieza fue colada por la técnica de cera perdida. La boca del molde se encontraba en la zona superior central de la pieza y es probable que contara con dos canales derivadores hacia cada uno de los costados. Hayan estado o no estos canales, hubo un problema de entrampamiento de aire o de enfriamiento del metal y, como resultado, el sector inferior de la placa no se llenó debidamente. Por tal razón los detalles inferiores de la figura central no quedaron marcados. El extremo inferior izquierdo de la pieza no llegó a recibir material y se formó un vértice redondeado. Del brazo izquierdo de la figura no cuelga ningún instrumento, como es habitual en otras placas del tipo "Sacrificador". La hipótesis inicial al respecto expresaba que el eventual instrumento no se habría impreso, como ocurrió con los pies, debido al defecto de fabricación que afectó al costado izquierdo de la pieza. No obstante, las observaciones microscópicas sugieren que nunca fue planeada la inclusión de tal instrumento.

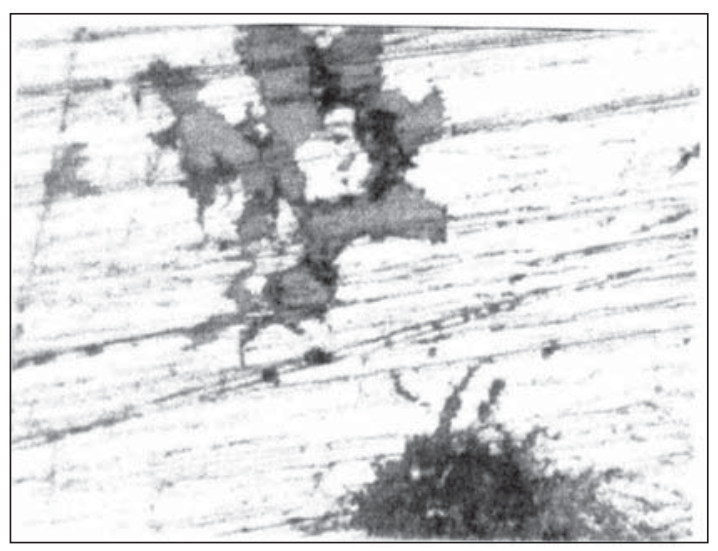

Figura 8. Placa $\mathrm{N}^{0}$ 3: metalografía (200x) en zona de fisura, con inclusiones de óxidos.

\section{Discusión}

La información obtenida de los estudios efectuados permite reconocer tanto similitudes como particularidades en las características técnicas de cada pieza. Los tres ejemplares fueron elaborados utilizando el método de la cera perdida y, en todos los casos, la boca de colada principal desembocaba en la parte superior, donde se encuentran los apéndices cefálicos. El uso de este método de colada se ajusta a las cualidades metalográficas detectadas en los materiales pero también es inferible por la calidad y complejidad de realización de algunos detalles. Puede destacarse, en tal sentido, las cabezas de aves de los apéndices superiores conformadas en tres dimensiones en la pieza $\mathrm{N}^{\mathrm{o}} 1 \mathrm{y}$, en la pieza $\mathrm{N}^{\mathrm{o}} 2$, el morro hueco del aditamento zoomorfo que cubre el rostro del personaje central. Luego de extraídas de los moldes, las placas fueron sometidas a operaciones de retoque y acabado de distinta envergadura.

Por lo menos en las piezas $\mathrm{N}^{\circ} 1$ y $\mathrm{N}^{\circ} 2$, la cavidad del molde habría estado recubierta con una emulsión de fosfato de calcio. En la pieza $\mathrm{N}^{\mathrm{o}} 3$ no se encontró ningún indicio al respecto, pero debe recordarse que este ejemplar fue objeto de repetidos eventos de limpieza, aparentemente en épocas modernas. El uso de la emulsión mencionada, que podía lograrse a partir de huesos calcinados y molidos, se transformaría en una práctica habitual en la producción metalúrgica del N.O.A. durante los siglos que siguieron y parece haber estado marcadamente restringida a la región (L. R. González 1992 y 1997). Por un lado, los casos estudiados sugieren que habrían sido los artesanos Aguada los que iniciaron esta modalidad tecnológica y, por otro, avala la hipótesis que las placas de que nos ocupamos fueron elaboradas en la región, tal como fuera propuesto a través de otras líneas de análisis. Todas las piezas muestran algunos defectos de fabricación, relacionados con un incompleto llenado del molde por inadecuada evacuación de gases (cuestión crítica en un molde de cera perdida; L. R. González 1994b) y enfriamiento del metal de colada. Considerando el grado de detalle de los motivos iconográficos y la dificultad de realización de cada placa, la $\mathrm{N}^{\mathrm{o}} 3$ podría ser considerada como la de menor calidad. De igual modo, la información metalográfica indica la presencia de óxidos de cobre en los espacios interdendríticos, atribuibles a una incompleta reducción de las menas originales. 
Teniendo en cuenta los contenidos de estaño presentes en las tres placas, y sumando la información conocida al respecto de las otras tres analizadas por otros autores, puede afirmarse que los artesanos Aguada trabajaron con bronce "verdadero". Los porcentajes detectados en las cinco placas son variables (Gráfico 1) pero habida cuenta de la inexistencia de asociaciones de minerales de cobre y estaño en el N.O.A. no son admisibles explicaciones basadas en la contaminación de las menas para dar cuenta de la producción del bronce. Por el contrario, la aleación resultó de una definida elección tecnológica que implicó, en primer lugar, proveerse de los distintos minerales en localizaciones separadas, con la inherente planificación logística. En segundo lugar, aumentó la complejidad de las operaciones de transformación de las menas, en términos de energía y tiempo de trabajo aplicado $\mathrm{y}$, sobre todo, de habilidad y entrenamiento de la mano de obra. Debe tenerse presente que el agregado de estaño al cobre modifica las propiedades del metal obtenido (p.e., la dureza), haciéndolo adecuado para la manufactura de herramientas de corte (Hosler 1994). Por supuesto, en bienes como las placas, la dureza no representaba una propiedad significativa. Al respecto, se ha manifestado

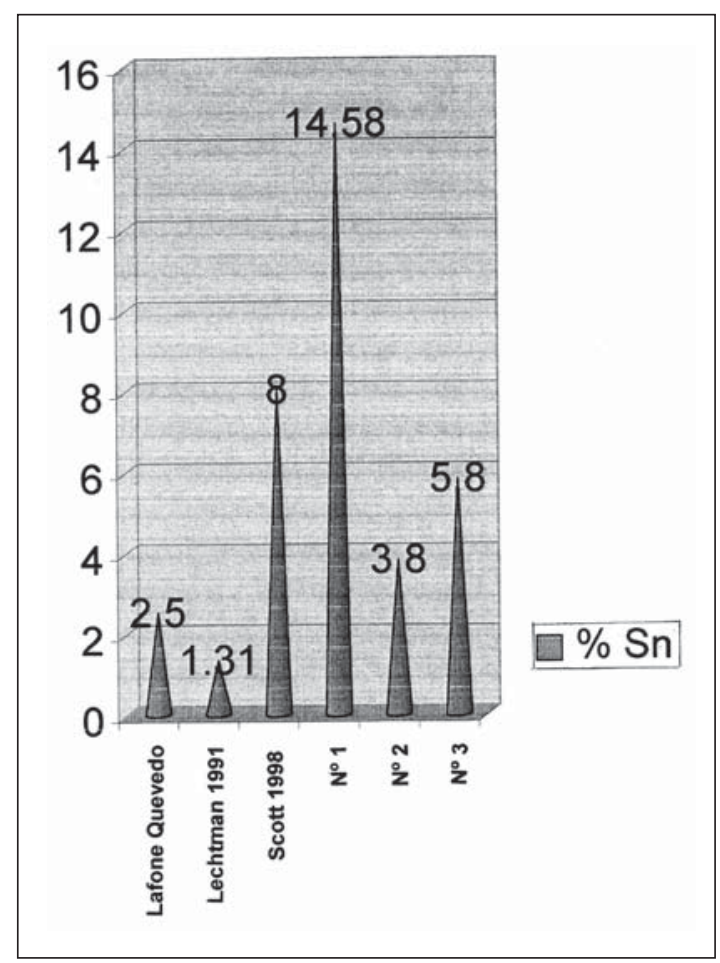

Gráfico 1. Contenidos de estaño en placas analizadas. que, en los Andes, el interés por desarrollar las aleaciones cobre-estaño parece haber residido en las propiedades del bronce para servir al despliegue y ostentación de status diferenciales y la comunicación de mensajes religiosos (Lechtman 1984: 45 y 1988: 369). En este sentido, el agregado de estaño al cobre, además de lo ya referido, involucra un cambio en el color del metal, del rojo al dorado, variable según las proporciones logradas. El color dorado remite a cultos heliocéntricos, cuestión ampliamente desarrollada en relación con las placas Aguada (Pérez Gollán 1986; A. R. González 1992; A. R. González et al. 2000). No obstante, es necesario tener en cuenta consideraciones eminentemente técnicas: la adición de estaño baja el punto de fusión del metal y, sobre todo, mejora notablemente las condiciones de colada (Coghlan 1975; Craddock 1995; Tylecote 1979 y 1987), debido a que el elemento reacciona con los gases disueltos en el material fundido, previniendo la formación de vesículas y poros (Cowell y La Niece 1991: 75). Estas cuestiones pudieron ser de suma importancia para lograr piezas tan difíciles, por sus detalles, como las tratadas y utilizando, además, moldes de cera perdida.

El vacío de datos sobre la procedencia de algunas de las piezas atenta contra la posibilidad de avanzar en propuestas surgidas de comparar la representación de los elementos que componen los materiales. Las dos piezas sobre las cuales se tienen referencias más sólidas respecto de su asignación geográfica, las placas Lafone Quevedo y Bercheni, muestran valores muy opuestos en la proporción de estaño (ver Gráfico 1). La segunda de las mencionadas es la que puede generar mayores dudas en relación con la autenticidad de su procedencia. No obstante, corresponde consignar que un objeto asignado a Aguada (Figura 9), procedente de Jujuy e ilustrado por A. R. González (1998: 93), muestra extraordinarias similitudes con la placa Bercheni, lo que apoya la idea que esta proviene de la región.

¿A que puede obedecer la disímil proporción de estaño en las diferentes placas? La respuesta más simple es a una azarosa circunstancia de fabricación. Dicho de otra manera: los artesanos trabajaban empíricamente y estaban incapacitados para dosificar con total precisión el contenido de aleante. No obstante, esta explicación puede ser la adecuada para diferencias de pocos puntos pero es de difícil aplicación para dar cuenta del alto 


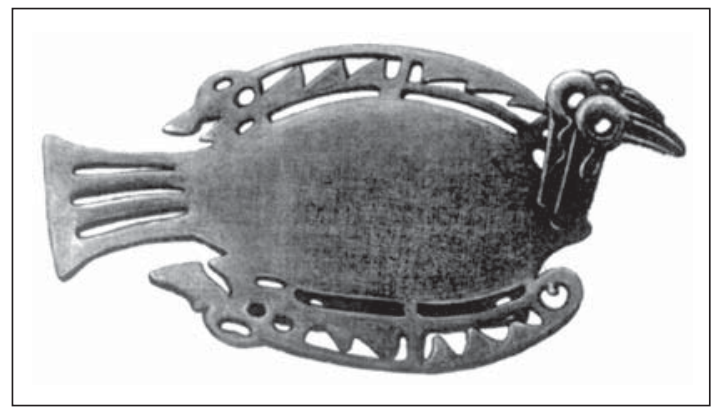

Figura 9. Adorno procedente de Jujuy (tomado de A. R. González 1998: 93). Compárese con la Placa $N^{\circ} 1$.

porcentaje detectado en la Bercheni y que sugiere que, en gran medida, responde a una dosificación intencional. Una hipótesis en tal sentido es que los disímiles contenidos de aleante se relacionen con la mayor o menor disponibilidad que tenían los artesanos de las menas correspondientes. En el N.O.A., los minerales de estaño constituyen un recurso relativamente escaso comparado con los de cobre y los fundidores de determinadas zonas pudieron tratar de "cuidar" su consumo, utilizando las dosis mínimas que contribuyeran a otorgar al metal ciertas condiciones valorizadas. De ello puede desprenderse que el taller donde fue fabricada la placa Bercheni no habría tenido problemas con el aprovisionamiento de menas estañíferas. Al respecto, puede ser de utilidad tener en cuenta la inserción regional de la pieza. Si bien los datos sobre análisis de composición disponibles son todavía escasos, sabemos que, por lo menos a partir del período de Desarrollos Regionales (ca. 850-1410 DC), en el norte del área valliserrana los contenidos de estaño en los bronces tienden a ser más altos que en los territorios más meridionales. En cuanto al primer caso, el promedio de aleante en 31 bronces analizados se ubica en $13.44 \%$, mientras que para el área valliserrana centro-sur, a partir de 66 piezas se estableció un promedio de $4.53 \%$ (L. R. González 2001; Gráfico 2). De igual modo, se ha documentado que en la Quebrada de Huamahuaca, la práctica de recubrir los moldes con una emulsión de fosfato de calcio se encontraba vigente hacia el 1200 DC (Tarragó y L. R. González 1998). Vale decir que, desde una óptica técnica, también podría plantearse que la placa Bercheni fue producida en el área donde fue reportado su hallazgo.

En los análisis químicos efectuados sobre las tres piezas no fue detectado arsénico, aunque no pue- de descartarse que, si el elemento se encontraba presente en un procentaje menor al $0.5 \%$, podría haber escapado a la sensibilidad de la técnica analítica utilizada. De todas formas, para el disco de Lafone Quevedo se reportó apenas $0.3 \%$ de arsénico y para la placa estudiada por Scott (1998) algo más, 0.8\%. Lechtman (1991) no consignó este elemento en su análisis. Sin embargo, los datos indican que los artesanos estuvieron elaborando bronce estañífero y la presencia de arsénico puede ser interpretada como una mera contaminación a partir de las cualidades del mineral de cobre utilizado. En estos casos, la representación del arsénico en los metales es dependiente de las condiciones de fundición de las menas y de los tratamientos técnicos posteriores (L. R. González 2001). Scott (1998: 101) también detectó en su ejemplar, antimonio en una proporción relativamente apreciable $(2.7 \%)$, pero consideró que el elemento había ingresado como impureza (Fester 1962).

Otro aspecto que merece señalarse es la presencia, en las tres placas estudiadas, de cavidades que parecen haber sido planeadas para engarzar piedras ornamentales, como ya fuera sugerido por A. R. González (1992: 250). Tal ornamentación no ha llegado a nuestros días, pero sospecho que la práctica debe de haber sido más común de lo que podría pensarse y su escasa representación en el registro de metales conocidos obedece a la

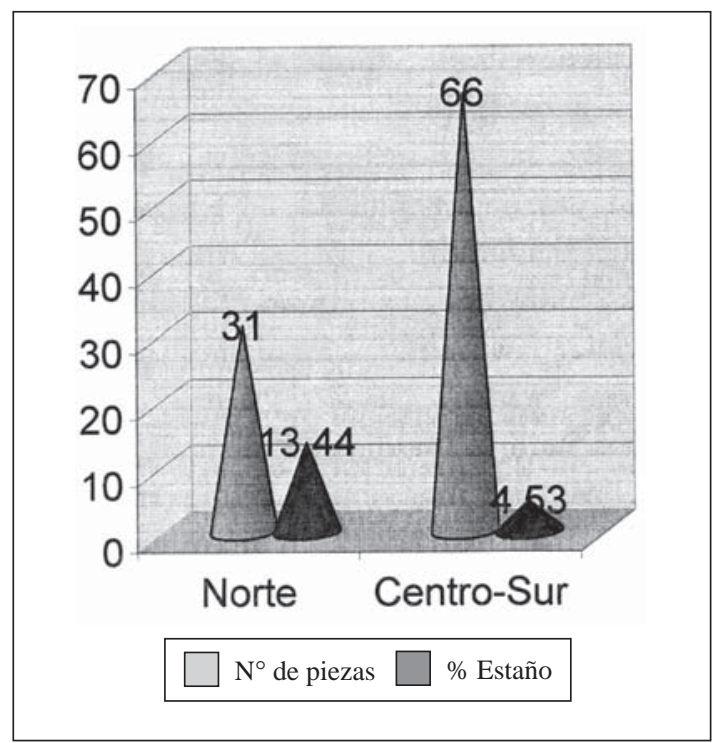

Gráfico 2. Contenidos de estaño en bronces del Período de Desarrollos Regionales. 
degradación de los adhesivos utilizados. Recientemente ha sido analizado un disco de bronce de momentos tardíos con figuras zoomorfas caladas en su perímetro, procedente de San Juan (L. R. González et al. 2001). La mayor parte de estas figuras conservan en sus ojos piedras que, mineralógicamente, fueron identificadas como turquesas. Estas piedras están unidas al metal con una resina de composición compleja, probablemente de origen vegetal, la cual se conservó en virtud de excepcionales condiciones del ambiente de depositación.

\section{Conclusiones}

Los resultados de los estudios llevados a cabo corroboran lo ya adelantado por otros autores en relación con el alto valor simbólico que debieron acreditar este tipo de objetos, considerando en esta oportunidad, la inversión de trabajo, el conocimiento técnico involucrado y la organización de la producción subyacente. No sólo es destacable la maestría de los artesanos para plasmar en metal los sutiles detalles iconográficos previamente realizados en un modelo de cera, sino también el control evidenciado sobre una multitud de variables físico-químicas interactuantes y del comportamiento de los materiales sometidos a situaciones extremas de temperatura y tensión. Los defectos de fabricación que fueran señalados, más notables en una pieza que en otra, lejos de opacar el trabajo de los fundidores, alertan sobre los problemas que debieron ser resueltos.

Como se dijera, las menas utilizadas para preparar las aleaciones debieron ser obtenidas en yacimientos minerales diferentes y, para el caso del estaño, de localización puntual. Esta circunstancia pone de manifiesto, además de un acabado conocimiento de la geología regional, una formación minera que permitía seleccionar las menas adecuadas a los fines propuestos. No sabemos si los mineros eran los mismos que se encargarían luego de la fundición. Tampoco, de tratarse de equipos de trabajo distintos, si estaban ligados por una adscripción social común. Pero, cualquiera fuera el caso, todo apunta a indicar que el aprovisionamiento de los minerales no constituyó una actividad casual sino organizada y legitimada a través de una instancia sociopolítica. Es presumible, asimismo, que el aprovisionamiento de la cera para construir los modelos haya constituido una tarea de similar importancia a la de los minerales aun- que, sin conocer la ubicación de los talleres, es difícil avanzar en propuestas acerca del uso de cera de abejas o de vegetales (L. R. González 1994b).

La complejidad inherente al proceso productivo de las piezas y los resultados obtenidos en los estudios sugieren la intervención de artesanos especializados y entrenados en una tradición técnica, que no es congruente con una dedicación ocasional y de alcance doméstico. Por el contrario, puede plantearse que estos artesanos desarrollaron sus tareas en un marco institucional formalizado y en el cual la producción de placas (y otros bienes suntuarios Aguada) constituían una actividad con auspicio y reconocimiento social. Parece claro que el "estilo tecnológico" y las innovaciones desarrolladas (que marcarían la trayectoria de la metalurgia del N.O.A. en los siglos que siguieron), no estuvieron sujetos a decisiones tendientes a optimizar las relaciones de las comunidades con su ambiente natural, sino que dependieron de niveles superestructurales de la organización social. En este sentido, se recordará que se propuso, para explicar la amplia distribución surandina de las placas, que shamanes itinerantes pudieron haberlas llevado como parte de la difusión del culto. De acuerdo a ello, la tecnología aplicada en la producción de estas piezas debió acomodarse a las cualidades físicas requeridas de ellas como materializadoras del mensaje religioso. Esta dialéctica de determinaciones y sobredeterminaciones entre el nivel de desarrollo de las bases productivas y la ideología dominante se muestra con claridad si consideramos la posibilidad que la placa Bercheni haya sido manufacturada en la misma región de su hallazgo. Por lo menos para ese caso, podría proponerse que los representantes religiosos Aguada fueron también los metalurgistas, lo cual les otorgaría una fuente adicional de poder al sumar al conocimiento esotérico el conocimiento técnico necesario para divulgar, en bronce, los principios y los símbolos de los órdenes cósmico y social.

Agradecimientos Un especial reconocimiento al Dr. Edgardo Cabanillas y a Ricardo Montero, por su inestimable colaboración en los análisis de laboratorio y la evaluación de los resultados. Le agradezco también al Dr. Jose A. Pérez Gollán, quien me facilitó el manuscrito preparado con A. R. González y A. M. Llamazares. El Lic. Javier Nastri fue quien me refirió la existencia de una placa inédita en el Museo Casa de Ricardo Rojas, de Buenos Aires. 


\section{REFERENCIAS CITADAS}

BILONI, H., F. KISS, T. PALACIOS y D. VASALLO, 1990. Análisis metalográfico de la placa de Lafone Quevedo. Serie Difusión 7, CIC, Buenos Aires.

BOVISIO, M., 1994. Reconstrucción de una identidad: Metodología para el análisis de modelos cognitivos andinos en la plástica precolombina argentina. En Arte, historia e identidad en América Latina, XVII Coloquio Internacional del Arte, pp. 925-938. UNAM, México D.F.

BRAY, W., 1991. La metalurgia en el Perú prehispánico. En Los Incas y el Antiguo Perú, pp. 58-81. Sociedad Estatal Quinto Centenario, Madrid.

BRONSON, B., 1996. Metals, specialization, and development in Early Eastern and Southern Asia, En Craft specialization and social evolution: In Memory of $V$. Gordon Childe, B. Wailes (Ed.), pp. 177-186. University of Pennsylvania, Philadelphia.

COGHLAN, H., 1975. Notes on the prehistoric metallurgy of copper and bronze in the Old World. Ocassional Papers on Technology 4, Pitt Rivers Museum, University of Oxford, Oxford.

COWELL, M. y S. LA NIECE, 1991. Metalwork: Artifice and artistry. En Science and the past, S. Bowman (Ed), pp. 74-98. British Museum Press, London.

CRADDOCK, P., 1995. Early metal mining and production. Edinburgh University Press, Edinburgh.

CHILDE, V. G., 1930. The Bronze Age. Cambridge University Press, Cambridge.

__1936. Man makes himself. Pitman Publishing, London.

EASBY, D., 1966. Early metallurgy in the New World. Scientific American 214 (4): 73-81.

EMERICH, A., 1992. Sudor del sol y lágrimas de la luna. En Oro del Antiguo Perú, Banco de Crédito del Perú, pp. 195-235. Lima.

FESTER, G., 1962. Copper and copper alloys in ancient Argentina. Chymia 8: 21-31.

GONZALEZ, A. R., 1959. A note on the antiquity of bronze in N. W. Argentina. En Actas CIA 33, T II, pp. 384-397, San José.

_-1992. Las placas metálicas de los Andes del Sur. KAVA, Berlin.

—_1998. Cultura La Aguada. Arqueología y diseños. Filmediciones Valero, Buenos Aires.

GONZALEZ, A. R., J. A. PEREZ GOLLAN y A. M. LLAMAZARES, 2000. Nuevos ejemplares de placas metálicas de los Andes del sur. Boletín del Museo Chileno de Arte Precolombino (en prensa).
GONZALEZ, L. R., 1992. Fundir es morir un poco. Restos de actividades metalúrgicas en el valle de Santa María, pcia. de Catamarca. Palimpsesto. Revista de Arqueología 2: 51-70.

-1994a. El bronce que sonríe. Metalurgia prehispánica en el Noroeste Argentino. Ciencia Hoy 27: 25-31.

_ 1994b. El caso de la cera perdida. Metalurgia prehispánica y recursos en el valle de Yocavil. Relaciones de la SAA 19: 171-190.

-1997. Cuerpos ardientes. Interacción surandina y tecnología metalúrgica. Estudios Atacameños 14: 189-210.

-1999. Bronce bajo el sol. Metalurgia prehispánica en el Noroeste Argentino. En Masked Histories, P. Stenborg y A. Muñoz (Eds.), pp. 97-131. Etnologiska Studier 43, Gotemburgo.

2001. Tecnología y dinámica social. La producción metalúrgica prehispánica en el Noroeste Argentino. Tesis Doctoral, Facultad de Filosofía y Letras, Universidad de Buenos Aires.

GONZALEZ, L. R. y A. VARGAS, 1999. Tecnología metalúrgica y organización social en el Noroeste Argentino prehispánico. Estudio de un disco. Chungará 31 (1): 527.

GONZALEZ, L. R., E. CABANILLAS y T. PALACIOS, 1999. El pozo y el tumi. Arqueometalurgia del Noroeste Argentino. Cuadernos del INAyPL 18: 207-222.

GONZALEZ, L. R., E. CABANILLAS y T. PALACIOS, 2001. Un paso al más allá. Nuevos análisis de objetos prehispánicos de metal del Noroeste Argentino. En Actas XIV Congreso Nacional de Arqueología Argentina, Rosario (en prensa).

HOSLER, D., 1994. The sounds and colors of power. The sacred metallurgical technology of Ancient West Mexico. MIT Press, Cambridge.

LAFONE QUEVEDO, S., 1890. Notas arqueológicas. A propósito de un objeto de arte indígena. Anales del Museo de La Plata 1: 3-13.

LAHIRI, N., 1995. Indian metal and metal-related artefacts as cultural signifiers: An ethnographic perspective. World Archaeology 27 (1): 116-132.

LAMBERT, J., 1997. Traces of the past. Addison-Wesley, Reading.

LECHTMAN, H., 1980. The Central Andes: Metallurgy without iron. En The Coming of the Age of Iron, pp. 267334. Yale University Press, New Haven.

-1984. Precolumbian surface metallurgy. Scientific American 250 (6): 38-45. 
-1988. Traditions and styles in Central Andean metalworking. En The beginning of the use of metals and alloys, R. Maddin (Ed.), pp. 344-378. MIT Press, Cambridge.

-1991. La metalurgia precolombina: Tecnología y valores. Análisis técnicos. En Los Orfebres olvidados de América, Museo Chileno de Arte Precolombino, pp. 9-18 y 71-95. Santiago.

- 1996. El bronce y el Horizonte Medio. Boletín del Museo del Oro 41: 2-25.

-1999. Afterword. En The social dynamics of technology, M. A. Dobres y C. Hoffman (Eds.), pp. 223-232. Smithsonian Institution Press, Washington D.C.

PEREZ GOLLAN, J. A., 1986. Iconografía religiosa andina en el Noroeste Argentino. Boletín Instituto Francés de Estudios Andinos XV (3-4): 61-72.

- 1991. La cultura de La Aguada vista desde el valle de Ambato. En Arqueología del Ambato, pp. 157-173. Publicaciones del CIFFyH, Arqueología 46, Universidad de Córdoba.

SCOTT, D., 1998. Technical examination of South American metals: Some examples from Colombia, Perú and Argentina. Boletín del Museo del Oro 44-45: 78-105.

SHIMADA, I., 1994. Pre-hispanic metallurgy and mining in the Andes: Recent advances and future tasks. En In Quest of mineral wealth: Aboriginal and Colonial mining in Spanish America, A. Craig y R. West (Eds.), pp. 37-73. Lousiana State University, Baton Rouge.
TARRAGO, M. y L. R. GONZALEZ, 1996. Producción especializada y diferenciación social en el sur del valle de Yocavil. Anales de Arqueología y Etnología 50/51: 85108.

1998. La producción metalúrgica prehispánica en el asentamiento de Tilcara (Prov. de Jujuy). Estudios preliminares sobre nuevas evidencias. En Los desarrollos locales y sus territorios. Arqueología del N.O.A., M. B. Cremonte (Ed.), pp. 179-198. Universidad Nacional de Jujuy, San Salvador de Jujuy.

TARRAGO, M., L. R. GONZALEZ y J. NASTRI, 1997. Las interacciones prehispánicas a través del estilo: El caso de la iconografía santamariana. Estudios Atacameños 14: 223-242.

TYLECOTE, R., 1979. A history of metallurgy. Metals Society, Londres.

- 1987. The early history of metallurgy in Europe. Longman, Londres.

WEST, R., 1994. Aboriginal metallurgy and metalworking in Spanish America: A brief overview. En In quest of mineral wealth. Aboriginal and Colonial mining and metallurgy in Spanish America, A Craig y R. West (Eds.), pp.5-20. Lousiana State University, Baton Rouge.

ZIOBROWSKI, C., E. CABANILLAS, T. PALACIOS y L. R. GONZALEZ, 1996. Estudio de aleaciones cobre-arsénico. Boletín del Museo del Oro 41: 131-143. 
